\title{
Implications of Global Economics Crisis on the Nigeria's Health Sector, 2008-2011
}

\author{
Eme Okechukwu Innocent \\ Edeh, H.C \\ Department of Public Administration and Local Government Studies, University of Nigeria, Nsukka \\ Email: okechukwunncnt@yahoo.com, okechukwunncnt@gmail.com \\ Uche, Okala A. \\ Uche, ljeoma B. \\ Department of Social Work, University of Nigeria, Nsukka
}

\section{Doi:10.5901/ajis.2014.v3n6p455}

\begin{abstract}
The crisis in Nigeria's health sector was in evidence when victims of the August 26, 2011 bombing of the United Nations House, Abuja, were flown to South Africa for medical treatment neither the National Hospital, Abuja, reputed to be the best equipped public health establishment with country, nor the university teaching hospitals ere deemed good enough. The referral to a South Africa health facility is handy a surprise, given the frequency of foreign medical trips by Nigerian Public offices, as acknowledges by President Jonathan at the 50th anniversary of the region medical association in April 2010. But Current Finance Minister; Ngozi Okonjo-Iweala, wants lost implications and with other consequences of the poor health care delivery system to be considered. This article seeks to consider the challenges facing health care delivery in Nigeria and articulates the challenges to include inadequate health facilities, decay where they exist, lade of motivation, high turnover of qualified personnel incessant strike actions among others. The paper concludes by positing that these difficulties are well-known and should be the focal point of remedial actions by the their tiers of government by providing basic infrastructures, stable power and better conditions of service.
\end{abstract}

Keywords: Economic meltdown, Health crises, Service delivery, Budget, Brain drain, Infrastructural decay and Medical tourism.

\section{Introduction}

In the midst of the global economic and financial crisis, health constitutes a common denominator between the poor and rich nations. Calamities, and pandemics are bound to occur and some cannot be predicted. The wake of the Avian \& Ecoli flu recrudescence forms typical examples. They have created, global without warning, sudden health emergency state with every one being at risk across the globe and according to the World Health Organization's Director-General Margaret Chan, "it really is all of humanity that is under threat". Public places, and schools are being shut down and affected people being asked to stay at home. The outcome is a further drop in economic output as a result of intra- and inter-continental trade cycling further econo-financial crisis, more health instability increased morbidities and mortalities.

The crisis, which 'was triggered by the credit crunch within the US sub-prime mortgage market' (Ajakaiye and Fakiyesi, 2009:1) raised serious concerns over its likely impact on healthcare delivery not just in the less developed countries but even also in the OECD countries as well. It was projected that the crisis would have serious negative impact on healthcare, particularly in the less developed countries, through a number of channels. These include reduction in household incomes; fall in remittances, reduction in national health budgets, reduction in ODA, reduction in health-related overseas private assistance (say from foundations and fall in commodity prices.

Overall, it was predicted that the impact of the economic meltdown on health delivery would be grave. The World Bank (2008), for instance, predicted that a decline in GDP of one or more would be grave. The World Bank for instance, predicted that decline GDP of one or more points increases average infant mortality by 7.4 per 1000 births for girls and to 1.5 per 1000 births for boys. It was also feared that the falling commodity prices occasioned by the crisis would affect the capacity of many African countries, particularly the oil exporters, to fund social services, including health, and that increased poverty would result in worse nutritional status, which would in turn affect the quality of health. 
These concerns were reinforced by the fact that overall healthcare financing in Sub-Saharan African has been constrained, not only in terms of the volume of funds available, but also by the fragility of the underlying governance structures that have not adequately addressed efficiency of resource allocation and use (Musau 2010:1). With particular reference to Nigeria, Adekanye et al (2009:7) pointed out that the government had warned concerning the 2009 budget that "the budget is not going to be workable and that means budget cuts across all the sectors including health.

Inadequate and obsolete equipment in Nigerian hospitals had over the years contributed to the exodus of Nigerian doctors and other health personnel abroad in search of better opportunities. Indeed, poor healthcare services in the country have contributed to increase in mortality rate in the country. Statistics of health indices from international agencies point to the fact that at 50 , Nigeria is still far from achieving the minimum required health standard. A recent World Health Organisation, WHO (2009), report shows that one million Nigerian children die at birth out of the nine million infant deaths recorded globally. The most disturbing part of Nigerian health policy is the culture of government sponsoring public officials abroad for treatment instead of making provision for adequate health care for Nigerians. For many Nigerians, these acts have continued to expose the lack of commitment and sincerity of government towards tackling the issue of healthcare delivery in the country.

The welfare package of doctors and other medical personnel's has been a burning issue in recent years. Early this year, public hospitals were paralysed due to strikes by medical doctors over poor welfare packages. Tokunbo Ola, a medical doctor, argued that doctors in Nigeria are the lowest paid. So, he would want President Jonathan to address the issue of doctors' pay by implementing a universal doctor's salary scale in order to avert frequent strikes by them. Doctors in Lagos had paralysed health services in public hospitals for over three months over the issue of new salaries.

Successive governments have tinkered with some health policies in the past. For instance, Primary Health care was the cornerstone of the Ibrahim Babangida regime's health policy. Many Nigerians would want President Jonathan to pay more attention to primary health care which has almost gone into extinction. The Present Sad situation of the health sector in Nigeria, taking references from World Health Organization, United Nations Development Programme, the National Bureau of Statistics, National Population Commission and the Demographic Health Survey, can be further gleaned from these highlights:

- Nigeria has an estimated population of about 145 million people

- Healthy life expectancy at birth male / female: $41 / 42$

- Probability of dying under fire (100 have birth): 191

- Probability of dying 15 and 60 years male/female (per 1000 population) 447/399

- The under-five mortality rate is presently put at 157 children per thousand, meaning that 1 out of 6 children born die before their fifth birthday- half of this number actually involve those less than one year old.

- Another points of interest have are the health indices that concern the adult female population, which is equally noted to be among the very worst in the world.

- On the average, some 800 per 10,000 women die in Nigeria every year due to pregnancy related causes. In some regions, the figure is actually more than twice the quoted average.

- Three quarters of all material deaths occur during delivery and the immediate post-partum period (Akinrogunde, 2011:1, 4).

From the aforementioned, it is stating the obvious to point out that the prevailing picture of the health sector in Nigeria looks rather gloomy and very challenging. According to Yusuf, all intent and purpose, the figure is very realistic because you have all the factors contributing to mortality of human beings at early life still very rampant in Nigeria. Expatiating, he says:

Deaths from preventable and non-preventable diseases are still very high, as well as deaths from accidents, and chronic illnesses like cancers. Look at maternal and infant mortality for instance, we are now the ors tint he entire world. I am quick to always remind people that the best way to assess the level of healthcare in Nigeria is to go to your towns and villages and look at the surroundings and see whether you ill find any healthcare facility. You hardly find any there.

Though Yusuf admits that people still live up to 90 years, but they are rather few. As much as he will like to admit that there are people who survive up to 90 years in Nigeria, but it is like living by chance. Anybody who is seriously sick in this country is doomed because our facilities quite unfortunately cannot take care of very serious illnesses. This is why you really cannot stop those who can afford treatment abroad to travel out of the country. From the above explanations, we can posit that when the people are seriously sick, they die. And when the actuary officers collating these statistics visit such places, they do not find hospitals. And when they interview people in the neighourhood who report loss of their relations to either childbirths, deaths of children, or adults to road traffic accidents and what have you, they report 100 
percent mortality in those areas at the long run.

Yusuf is particularly pained to admit that the nation's healthcare pines under the yoke of poverty occasioned by dearth of equipment under funding, inadequate personnel, lack of a legal framework, among other limitations, a development he says is symptomatic of the general malady in the system. We all have inherited a decadent society. We all have inherited a decadent society. We have allowed our country to slide and we are all at fault. So we all need to come together as one united body called Nigeria and take our destinies in our hands and move Nigeria forward Yusuf (2008).

Additionally, funding for meeting the earlier targeted Millennium Development Goals continues to drop and the realization of these goals becoming a dream. The World Bank (2008) has warned that the global financial crisis could become "a human and development calamity" for the poor countries urging do not nations to speedy delivery of money they have pledged and consider giving more. The puzzle then is: Where are the funds formerly pledged going to come from in the beehive of the current economic and financial meltdown?

Recently, the Global Find to Fight AIDS, Tuberculosis and Malaria announced that it is facing a $\$ 5$ billion funding gap through 2010. There also has been an increase in new funding request for eligible nations, the demand being much higher than expected. To meet the demand, more money is needed than what is currently made available. In December 2008 , the Global Fund grants were reduced by 10 percent, from $\$ 3.1$ billion to $\$ 2.75$ billion, although all program requests were approved. Recipients were asked to achieve the same goal with reduced funding through changes like cuts in overhead costs or funding lower cost options of pharmaceuticals (Akpo, 2009:33).

The fascinating inter-country economic and financial dependence places Nigeria in a very difficult poison as it is not left out in the global economic malady. The Nigerian government expenditure has become grossly affected as a result of recurrent fiscal budget deficits. The resultant poorer prognostic interplay is on health which forms a common denominator among the law, middle and high income earners and the under privileged in the polity. The paper therefore, $x$-rays the implications of the global economic meltdown in the Nigeria's health sector and the health of Nigerians.

\section{Theoretical Perspectives: Economic Meltdown}

In a generic sense, a common man's perception of global economic crisis, meltdown or down turn refers to a financial and investment distortion that started at one point (Wall Street, USA) which gradually but steadily affected all financial and investment institutions and economies in the world negatively. Tenuche and Agba (2009) conceived the concept as a recession. A recession is a downturn in a nation's economy. The consequences typically include increased unemployment, decreased consumer and business spending and declining stock prices. Ogunyele (2009) adds that recessions are typically shorter than the periods of economic expansion that they follow, but can be quite severe even if brief. Recovery is slower for some recessions than from others.

Adamu (2007) applied the concept more broadly by positing that it is variety of situations in which some financial institutions or assets suddenly lose a large part of theirs value. Kindleberger and Aliber (2005), Laeven and Valencia (2008) add that in the $19^{\text {th }}$ and early $20^{\text {th }}$ centuries, many financial crises where associated with banking panics, many recessions coincided with these panics. Other situations that are after called financial crisis include stock market crashes and bursting of other financial bubbles, currency crises and sovereign defaults.

The International Monetary Fund (IMF) (2009:1) has noted that the crisis reflects the confluence of several factors:

$>$ As in previous times (of economic recession) the pre- crisis period which was characterized by (I) surging assets prices that proved unsustainable, (ii) a prolonged credit expansion leading to accumulation of debt, (iii) the emergence of new types of financial instruments, and (iv) the inability of regulators to keep up (compare this with Nigeria's current banking crisis).

$>$ There was a new rapid expansion of securitization (not itself a new phenomenon), which changed incentives for lenders and lowered credit standards. Systems became fragile because balance sheets became increasingly complex (further complicated by increased use of off - balance sheet instruments) financial market players were highly leveraged and they relied on wholesale funding and external risk assessments. Cross - border spillovers intensified after the crisis broke out because financial institutions and market across borders were closely linked and the risks they bear are highly correlated (IMF, 2009).

The global financial crisis/meltdown also manifested in the following forms:

> Advanced economies are now suffering their worst downturn since the World War II occasioning dramatic decline in aggregate demand, leading to extensive destruction of jobs and livelihoods. Credit freeze which has led to virtual halt in lending for investment and consumption; the sharp drop in spending by businesses and 
households that led to massive layoffs which have further exacerbated the crisis and a myriad of other socioeconomic ripple effects too numerous to list here.

$>$ Productivity and economic growth rate has also fallen in china, brazil, India and other emerging market economies which have been dragged down from 6 percent in 2008 to about $31 / 4$ percent in 2009. This has been mainly due to falling export demands, subdued capital inflows, and lower commodity prices. Correspondingly, growth in all emerging market and developing economies, including sub- Saharan Africa slowed down to $3^{1 / 3}$ percent in 2008 (IMF, 2009:2).

The current global economic meltdown is characteristically contagious in view of the inextricable interlacing character of international economic relations. This is basically why the fiscal and monetary escapades of the world and leading financial and capital market exhibit roughly similar patterns. A critical study and tracking of the crisis throws up the futility of untamed predatory capitalism which modus operandi rests on making a tiny minority of the population overly rich while the teeming majority are deprived of the basic necessities of life. Onigbogi (2009:2) predicted that the whole world will be affected by the global economic meltdown "and all individual will be called upon to carry part of the cost of this debacle". Indeed it has been predicted that this crisis carries with it the seeds that will lead to the total collapse of the international financial system.

For our purpose global economic crisis refers to the complex interaction of macro economic mismanagement, in complete financial regulation, and defective corporate governance that is affecting different economies across the globe since 2007.

\section{Global Economic Crisis and Health delivery: The Problematique}

In response to concerns expressed by Member States of the World Health Organization (WHO), the Director General convened a high-level consultation before the opening of the Executive Board's $12^{\text {th }}$ session on the impact of the global financial and economic crisis on global health. The objectives were:

(a) To build awareness of the ways in which an economic downturn may affect health spending, health services, health seeking behaviour, and health outcomes;

(b) To make the case for sustaining investments in health; and

(c) To identify actions - including monitoring of early warning signs - that can help to mitigate the negative impact of economic downturns (WHO 2009).

The high powered consultation identified a number of pathways through which a recession in rich economies can affect other countries. According to the report export growth may decline this is already reflected in a major fall in commodity prices; foreign direct investment is likely to be reduced; sudden and dramatic falls in exchange rates are possible, although not inevitable; access to capital may become more difficult as interest rates and risk premiums rise; remittances may fall; and, most critically for the poorest countries, aid from donors may be significantly delayed or reduced (WHO 2009b:7).

The report stated further that total health spending in countries that have been affected by an economic downturn tends to fall, but not consistently (WHO 2009b:7) Reductions in total expenditure will have an impact on the composition of health spending. Also, many of the human consequences of recession are often hidden. For example, unemployment may erode women's growing economic independence, which will have its own health consequences. Similarly, coping strategies may exacerbate vulnerability (through, for example, increase exposure to HIV), reduced spending has impacts on health and education, and ultimately on the well-being of families and the development of the community as a whole (WHO 2009b:7).

The consultation suggested five areas where action at global, regional and country levels- with support from WHO will help to ensure that the health sector emerges from the crisis in good condition. These are:

- Leadership

- Monitoring and analysis

- Pro-poor and pro-health public spending

- New ways of doing business in international health (WHO 2009b:7)

Also, in a report prepared by the African Center for Gender and Social Development (ACGS) titled the 'African Perspectives of the Global economic and Financial Crisis, including the Impact on Health', it stated that the biggest concern is that the crisis may degenerate into a social development crisis on the continent as the recession deepens. It was also feared that it would have major effects on people's enjoyment of their human rights. The report predicted further that the crisis was likely to disrupt and in some instances reverse development gains, compromising progress toward the 
Millennium Development Goals (the MDGs), especially those aiming to reduce poverty, hunger, maternal and child mortality, and ensuring 'decent work for all' (ACGS 2010:1).

According to the report, the predicted impact of the crisis on health outcomes is grim. Increasing unemployment and poverty will lead to less food security and quality of nutrition, cutting back on already insufficient HIV treatment and care programmes because of the crisis. Child malnutrition and infant mortality might increase by 200,000 and 400.000 additional deaths in 2009 (UNICEF, 2009). Women, children, the poor, and minority groups, were expected to suffer disproportionately from the health impacts of the crisis (ACGS 2010:3).

The report identified two major channels through which the global financial and economic crisis will impact on social development including the health sector in Africa. These it classified as the supply side effects and the demand side effects. The supply side effects are those that directly affect the operating environment from the health sector and other social development services by affecting the supply of health and social services. The global financial and economic crisis is affecting the health sector directly by affecting the supply of health services, manifested mainly through government cutbacks in expenditure as a result of reduced revenues due to falling exports and as a result of potential reduction in ODA. This reduction in financing translates into reduced investment in health and availability of health services. The crisis thus threatens to reverse the gains that Africa had made on social development.

The financial and economic crisis through exchange rate devaluation is making it more expensive for countries to obtain imported equipment and drugs. Essential life medicines may become either unavailable or unaffordable (WHO, 2009b). Depreciation of currencies in the region will increase domestic prices of food in countries that are net importers of food and reduce access to food by vulnerable groups thereby affecting the nutrition and health outcomes of many.

The Demand side effects directly affect the health sector by affecting the household characteristics and its ability to demand health services. The global financial and economic crisis is affecting availability of income of the general population through loss of employment, and reduced remittances. Overall reduction in income will result in reduced consumption of health services due to lack of resources to pay to access health services, and reduced consumption of other goods such as education, food and nutrition security, that are essential for positive health outcomes.

It noted that Africa has already been facing challenges in securing health for its population, and that the crisis would only make the situation worse. African countries are constrained in their capacity to finance health as evidenced by the low levels of public sector health spending in many countries. The major challenges affecting public sector health financing include low domestic resource mobilization capacity, limited fiscal space, and constrained economic growth. Clearly, a significant gap remains between the current and needed financing for achieving the health MDGs. The financial crisis is likely to worsen the availability of domestic public resources that are allocated. Yet public resources are important for addressing health inequities (ACGS 2010:5)

The report observed that although some progress has been made in the past decade on some aspects of health that include measles vaccination, access to improved water supply, and reductions in HIV prevalence rates in some countries, very limited headway has been made on achieving the health MDG. Available data suggest very little improvements in reducing infant, child and maternal mortality in many African countries. The financial crisis can aggravate the situation resulting in reduced progress towards achieving the goals.

The World Bank (2009b) has warned that the global financial crisis could become "a human and development calamity" for many poor countries urging donor nations to speedy delivery of money they have pledged and consider giving more. Developing countries which form the World Bank's main constituency face serious consequences with the crisis driving more than 50 million people into extreme poverty, particularly women and children. It is obvious however, that the health sector gets hit the hardest by budget cuts in times of economic recession and women and children's health become badly affected. Over the past 25 years, over one million children died because of expenditure cuts by governments in response to economic downturns and the World Bank which is continuously receiving increasing number of loan requests has advised a refocus on specific health programs. Recently, the Global Fund to fight AIDS, Tuberculosis and Malaria announced that it is facing a \$5 billion funding gap through 2010 . There also has been an increase in new funding request for eligible nations, the demand being much higher than expected. To meet the demand, more money is needed than what is currently made available. In December 2008, the Global Fund grants were reduced by 10 percent, from $\$ 3.1$ billion to $\$ 2.75$ billion, although all program requests were approved.

Recipients were asked to achieve the same goal with reduced funding through changes like cuts in overhead costs or funding lower cost options of pharmaceuticals. Notably, more than $50 \%$ of the total public health spending in developing countries comes from aid commitments. Many of those countries do not have social safety nets to protect people from economic downturns. When national budgets are further squeezed because of falling tax revenues and falling donor contributions the social services for the poor are some of the first to be jeopardized. Foreign aid in economic 
recessions tends to be an easy target that does not have a very deep constituency. People living with HIVIAIDS and other diseases in developing countries risk seeing their treatments interrupted as a result of funding shortfalls. Decreases in aid for these programs affect individuals who are dependent on these resources for life saving drugs.

Nigeria is not immune to the global economic crunch that as triggered in august 2007 by the US sub-prime crisis. Profits that US and other businesses generated during recent years of economic expansion pushed investors to find investments generating higher rates of return, inevitably sending money after higher risk projects. As sub-prime mortgages in the United States began to reset to higher interest rates beginning to trigger residential defaults financial landmines hardwired into mortgage backed securities began to go off, devaluing and forcing holders of those securities to hoard cash to rebalance their asset sheets. Ultimately, banks from the United States to Europe to Asia were forced to severely restrict lending to shore up their cash reserves, reducing the amount of credit available to everyone across the global economy.

As a result, Nigeria has found its economic wherewithal under pressure on multiple fronts. Its currency, the naira, has declined over $20 \%$ relative to the American dollar since December 2008, and its stock market in Lagos has reached an almost two and a half year low, down 13 percent so far in 2009 after having fallen 46 percent in 2008. Investment is not likely to resume in the short term, with a broad global recession resulting in major global players downgrading, delaying or simply abandoning projects proposed prior to the economic crisis.

\section{Global Economic Crisis and Health Delivery in Nigeria: The Evidence}

In the preceding section we reviewed the concerns about, and the various projections on, the probable impact of the global economic crisis on healthcare delivery in sub-sub-Saharan Africa particularly with regard to funding. Summarily, it was feared that the crisis would lead to contraction in national budgets, including budgets for health, due to fall in commodity prices, drop in individual household incomes, fall in remittances, reduction in external/donor funding, etc. In this section, we proceed to examine the evidence on ground to determine empirically how the crisis has impacted on the funding of healthcare delivery, focusing specifically on Nigeria. In their analysis of the implication of the global economic crisis on the Nigerian economy, Ajakaiye and Fakiyesi (2009:26) stated that the share of the health sector in total expenditure between 1985 and 1999 as insignificant. Specifically, it was 1.09\% in 1990. This share increased from 1999 until 2002, when it dropped. The rise picked up again, but only gradually until 2008. They however pointed out that just as in education, the share of health in total expenditure in 2009 dropped from 6\% to $4.6 \%$ as is shown in Figure 1 below.

\begin{tabular}{|c|c|}
\hline Year & Budget in Billion \\
\hline 1999 & 16.18 \\
\hline 2000 & 20.445 \\
\hline 2001 & 44.652 \\
\hline 2002 & 63.171 \\
\hline 2003 & 39.686 \\
\hline 2004 & 52.40 \\
\hline 2005 & 71. \\
\hline 2006 & 85. \\
\hline 2007 & 123.922 \\
\hline 2008 & 138.17 \\
\hline 2009 & 154.57 \\
\hline 2010 & 161.84 \\
\hline 2011 & 235.8 \\
\hline
\end{tabular}

It is to be noted however that the figures for 2008 and 2009 in the table above represent estimated values. Empirically though, the evidence on ground tends to support these projections. As shown by Muanya (2009), an analysis of the 2008 and 2009 budgets show that contrary to the World Health Organization (WHO) recommendation and the Abuja Declaration by African countries to commit 15 per cent of their budget to health, the allocation for health as a percentage of the GDP actually decreased from six per cent in 2008 to five percent in 2009. (Mitik 2009:15) stated that the sectoral allocation to education and health in 2009 showed a $16 \%$ cut in education and $29 \%$ cut in health allocations. Similarly, the allocation to Human Immuno-Deficiency Virus (HIV)/Acquired Immune Deficiency Syndrome (AIDS) as percentage of the health budget decreased from 16 percent in 2008 to 12 percent in the 2009 budget (Muanya 2009:2).

Compounding the drop in the domestic budget for HIVIAIDS in Nigeria is the fall in offshore funding from the global 
power houses namely: PEPFAR and Global fund. The US President's emergency Plan for AIDS Relief (PEPFAR) was launched in 2003 by former US President George W. Bush to combat the global HIV and AIDS pandemic. The fund committed itself to providing US\$ 15 billion over five years (2003-2008) in support of the fight against HIV and AIDS. In July 2008, PEPFAR was reauthorized with an impressive US 48 billion approved for the 2009 to 2013 financial years. After assuming office, President Barack Obama announced his Global Health Initiative, which saw PEPFAR's budget extended to US\$ 51 billion, but available over a six year period (7). Owing, in part, to the global economic crisis however, the fund has effectively been flat lined for 2009 and 2010 with similar proposals for the following years. Medicines Sans frontiers (MSF) said PEPFAR aims to pass on the responsibility of direct funding treatment for patients to countries whenever possible, or else to the Global Fund. It however warned that cutbacks in rich world funding for Aids treatment could sentence millions of sufferers to death for lack of access to anti retroviral (ARV) drugs (Safaids 28 May 2010).

On its part, the Global fund to Fight AIDS, Tuberculosis and Malaria was established in 2002 to prevent and treat these three profound health concerns. The Global Fund collaborates with governments, civil society, the private sector and affected communities to combat the disease. It also works closely with other bilateral and multilateral organizations to further supplement existing efforts. Since its inception, the Fund has approved US $\$ 15.6$ billon to fund 572 programme in 140 countries. 57\% of the fund's money is channeled to sub-Saharan Africa. The Fund was however also not immune to the effects of the economic crisis. As a result, it has introduced certain changes in its funding plan.

Amongst the changes to funding which has to be made was that all grants approved for funding in Round 8 would have to be decreased by 10\%. Round 9 was to be postponed by six months and to be the only round in 2009 . Additionally, Phase II (years 3 through 5) of existing and future grants would be decreased by $25 \%$. The fund required US\$ 170 million to cover its 2008 programme commitments, and further faced a US\$ 4 billion shortfall in meeting its goals up to 2010. In an interview on April, 20 2009, Professor Micheal Kazatchikine, Head of the Global Available." Added that Round 10 funding will have to be suspended from 2010 to 2011 to replenish funds (Health-e 2010).

Pledges to the Fund announced on 5 October 2010, fell short of the lowest target set by the Fund as essential to continue current treatment rates. Governments and private donors committed USD 11.7 billon over three years after the Global Fund set a minimum target of USD13 billion. UNAIDS has noted that for the first time in 15 years, overall AIDS funding has not increased, even though HIV infection rates have continued to grow, with 33 million people currently estimated to be living with HIV. The Fund has hoped to raise $\$ 20$ billion to significantly reduce the growth of the epidemic, including the goal to eliminate the transmission of HIV from mother to child by 2015 (Health-e 2010).

Empirically, global funding for AIDS efforts fell flat in 2009 as a result of the economic meltdown, ending a six-year streak of annual donation increases. Overall, financial support for international HIVIAIDS assistance fell more than 1 percent to US $\$ 7.6$ billion in 2009, from US $\$ 7.7$ billion the previous year, according to a report from Kaiser family Foundation and the Joint United Nations Programme on HIVIAIDS. The report measured donations from the Group of Eight most industrialized nations, European Commission and other donor governments to low and moderate income countries, and noted difficulties interpreting real value as reporting cycles and currency fluctuated (Health-e 2010).

Perhaps, the import of this seemingly marginal drop would be better appreciated if we consider that until now, financial aid increased by at least 11 percentage points annually since 2002, when the groups donated US\$1.2 billion for international AIDS assistance. We need consider also that in 2008 alone, assistance jumped up 57 percent to US\$7.7 billion, US\$4.9 billion in 2007. So that even though the United States the world's largest donor nation increased its contribution by more than 11 percent to US $\$ 4.4$ billion in 2009, from US $\$ 3.95$ billion the year earlier, total international AIDS funding still fell approximately US\$7.7 billion short of the need in 2009. Of course, the effect of this shortfall in funding is spread evenly across the aid recipient countries.

Another channel through which it was envisaged that the global economic crisis would impact on healthcare delivery in Nigeria as in many other developing countries is the contraction in GDP. More than a year into the economic recovery, growth in high income countries remains tepid. The weak recovery has been attributed to sovereign stress in Europe, the reduction in global risk appetite, and the adoption by many governments of more sustainable fiscal policies, which, over the short term, inhibit growth. And as a result of these factors, global GDP was projected to increase by just 3.3 percent in 2012 (Helen Fisher 2009:3). As is evident, Nigeria, like many other countries in the region, recorded a negative GDP growth change in 2009 relative to year 2008. Her GDP fell from USD 207.116 billion in 2008 to USD 165.437 billion in 2009 signifying a -41.679 percentage change.

Perhaps, to fully appreciate the full import of this negative GDP growth change on the health sector in Nigeria, we need recall the projection by the World Bank that a decline in GDP of one or more points increases average infant mortality by 7.4 per 1000 births for girls and to 1.5 per 1000 births for boys (The World Bank cited in Adekanye et al, 2009:7). Another concern expressed with respect 0 the impact of the global economic crisis on healthcare delivery in 
Nigeria is the possible reduction in the quantum of Official Development Assistant (ODA) from governments of the industrialized nations under the aegis of the OECD.

Ajakaiye and Fakiyesi (2009:6) for instance feared that most countries' budget deficits are likely to increase considerably because of the rescue packages for banks and in some cases, the real sector, and that this could limit the developing countries' scope to receive development assistance. And even though the major donor countries had pledged to increase their ODA quotas to $0.7 \%$ of GDP, and to support achieving the MDGs by 2015 , there concerns that donors' promises would not be honoured in their entirety. Empirically, these fears turned out to be largely unfounded though. In 2009, total net Official Development Assistance (ODA) from members of the OECD's Development Assistance Committee (DAC) actually rose slightly in real terms (+0.7\%) to USD 119.6 billion, representing $0.31 \%$ of DAC members' combined Gross National Income (Income (GNI). The net bilateral ODA to Africa was USD 27 billion, representing an increase of $3 \%$ in real terms over 2008. The overall expected ODA level for 2010 was estimated at USD 108 billion (Fisher 2009:2). This is obviously a welcome departure from the negative trends that characterized the other sources of funding for healthcare delivery in Nigeria as in other countries of the sub-Saharan Africa owing to the global economic crisis.

\section{Health Implications}

In 1978, there were efforts to use health as the rout to socioeconomic development but this was followed almost immediately by fuel crisis, soaring oil prices, and the debt crisis of the early in 1980s. Mistakes were made in the international response to these crises when budgets were shifted away from investments in the social sectors, most especially health. The legacy of these errors is still being suffered by Nigeria today. History is about to repeat itself. The Nigerian economic climate and accompanying unemployment is likely to push more and more people into the poverty rolls. In the midst of all the crisis issues is often that people do not have access to health and even if they do, solutions to ailments are far fetched due to poor health sector funding from budget cuts. What is done in other sectors does not matter because one medical emergency, like the Avian flu recrudescence, can immediately destabilize not only family but a nation at large.

Different things are needed by different families whether such families are lo, middle or upper income families. The bottom line to their needs is healthcare. With already established links between income, employment and good health, the loss of coverage heightens the possibility of grave consequences for Nigerians' health. Nigerians are changing their health behaviour as a result of economic stress. A rising percentage of Nigerians are failing to obtain needed health care and cutting back on prescribed medications. Job cuts are also tied to higher levels of anxiety, stress and depression as well as greater risk of death from suicide and heart disease. As household budgets are stretched tighter, many families are forced to make unfortunate cutbacks which could mean buying less expensive, often less nutritional foods and having trouble paying for household energy need which can result in poor health outcomes especially for the children. These effects do not occur right at once but we will start seeing the consequences if the economic crunch persists. Many of such health consequences will likely be the result of cutbacks in community health services, essential staff and funding coupled with the strain of attempting to meet increasing demands. The recession is totally destabilizing the safety net and health care providers are no longer able to meet the explosive growth in demand for health care from patients especially the less privileged. Patients are now presenting with more complex and expensive medical conditions, and specialists who regularly opened their doors to patients in need are no longer accepting referrals due to non-payment of medical bills. The implications include the underlisted:

\section{Constitutional Impediments}

The Nigerian Health System though has its inherent complexities and is unnecessarily cumbersome. For example, the prevailing system has outlined in the 1999 Constitution place health on the concurrent list, meaning that all tiers of government have a defined role / responsibility to play at providing for the health needs of the populace. Generally, it is noted that the primary level of health care delivery is taken as the responsibility of local councils; the secondary level of care is noted as the responsibility of the state governments while the federal government is in change of the tertiary level of health came delivery.

Of course, for multifarious reasons, the outlined responsibility above have a lot of intermingles with respect to who is in charge at certain levels of health care provision. For example, a number of state governments have their own tertiary health institutions like teaching hospitals, while the federal government itself has created a number of institutional 
intervention agencies to come in at the primary level of health care. It is however, disappointing that such tertiary levels institution within the primary purer of the federal government such as the teaching and specialist hospitals and centers are not truly centers of excellence as a number of them are far from in reality.

In Nigeria today, even the "expertise" is said to be available in respect of these so called centers of excellence are lacking in tools that make them truly worthy of being referred to as tertiary health institutions. On this, one ask that of what relevance is a tertiary health institution that is lacking in modern diagnostic tools like the CT scans and MRI gadgets among others.

\section{Brain Drain}

While it is conceded that the salary and welfare packages of the federal government employed health practitioners have improved considerably when matched with their counterpart in other sectors elsewhere, thanks to the doggedness of their agitations for improved emoluments, this alone will not avert the collateral trend towards brain drain outside the country of the appropriate tools to function effectively are not put in place.

\section{Slow Implementation of NHIS}

Another area of health care challenge is the role the NHIS plays ... The National Health Insurance scheme which has been in place per enactment for more than 12 years now. To date, less than $5 \%$ of the populace had been keyed into the scheme, and that percentage comprise mostly federal government employees; very few state employees and organized private sector employees have signed on. The rest of the populace are not involved and there are no signs in view that there will be a radical change soon.

Even the Presidency /MDGs office's NHIS free medicare programme initiated two years ago for pregnant women and under five children in some local council in 12 states is already faltering due to paucity of found. For the health insurance scheme, this balance sheet scream failure and not a crawling success as the operators of the scheme and the profiteers from it went the populace to believe.

\section{Corruption}

While the agitation for more funds is very sign relevant, many also posited that even when conceded that very little get appropriated to health sector than understand by desired, the budgetary allocation for this sector hardly get to the target layers envisaged during budget implementation. Most of these funds get embezzled by corrupt officials and their collaborating suppliers and contractors (see Ndenle Grang \& Igbo)

\section{Framework for Advancement}

A healthy public is the most important piece of infrastructure needed for a strong economy. It is essential to learn from past mistakes and counter this period of economic recession by increasing investment in the health sector for the following reasons.

To protect the poor and underprivileged: Rising food and fuel prices along with employment insecurity are among the factors leading to downturn. In addition, access to healthcare or lack of access is often at the root of a family's financial problems. In this context, impoverishing health care expenditure that in "good" times push millions annually into poverty are likely to increase dramatically. Inevitably, it is the most vulnerable who suffer the most; the poor, the marginalized, children, women, disabled, the elderly and those with chronic illness. Stronger social safety nets are urgently needed t protect the most vulnerable in Nigeria.

To promote economic recovery: Investment in the social sectors is investment in human capital. Healthy human capital is the foundation of economic productivity and can accelerate recovery towards economic stability.

To promote social stability: Equitable healthcare distribution is a critical contributor to social cohesion. Social cohesion is the best protection against social unrest, nationally and internationally. Healthy, productive, and stable populations are always an asset, but most especially in a time of crisis.

To generate efficiency: Pre-payment with pooling of resources is the most efficient way of financing health expenditure. Out-of-pocket expenditure at the point of service is the least efficient and the most impoverishing already pushing millions below the poverty line each year. A commitment to national and private sector coverage not only 
protects the poor, it is the most affordable and efficient way of using limited resources.

To build security: A county that is greatly out of balance in health is neither stable nor secure. Robust health systems are essential to maintain surveillance and response capacity in the face of pandemic threats. The mistakes of the past must not be repeated as cyclical redundancy often terminates in decelerated growth of a nation. We cannot afford, in this time of crisis, to squander our investments, to abandon our drive for greater balance, which is firmly believed to be a mark of societal civilization. The Nigerian government and political leaders need to maintain their efforts to strengthen and improve the performance of the Nigerian health system, to protect the health of the people, and in particular of those most fragile, in face of the present financial and economic crisis.

\section{Concluding Remarks}

Many scholars/commentators have explained the crisis in various ways. These include: the inability of homeowners to make their mortgage payments, poor judgment by the borrower and/or lender, speculation and overbuilding during the boom period, risky mortgage products, high personal and corporate debt levels, financial innovation that distributed and concealed default risks, central bank policies, and regulation (Stiglitz, 2008). Avgouleas (2008) enumerated the causes of the crisis as: breakdown in underwriting standards for sub-prime mortgage; flaws in credit rating agencies' assessments of sub-prime Residential Mortgage Backed Securities (RMBS) and other Asset-Backed Securities (ABS); risk management weaknesses at some large US and European financial institutions; and regulatory policies, including capital and disclosure requirements that failed to mitigate risk management weaknesses (See Adamu 2009:5-6).

While these explanations are not irrelevant for the discussion of the recent global crisis, as explanations, they are grossly inadequate for the understanding of the complexities of a crisis that inheres primarily in the nature of the global capitalist economy. In the words of Eskor Toyo,

A capitalist economy is inherently a very unstable system. It reproduces inflationary tendencies, depressions, balance of payments desequilibraia, stock market booms and crashes, strikes and contradictory changes of government policies by its very nature Toyo (2002:13).

Toyo stated that the capitalist economy goes through various crises of short-term and medium term character, and also through long-term alternations of prosperity and relative stagnation. Today, according to him, it is also going through an existential crisis which is often called its general crisis. The short-term or medium-term crises are cyclical crises; balance of payments crises and stock market crashes. Basically, the capitalist economic is crisis-prone because of the decision making autonomy enjoyed by capitalist firms and because these firms engage in the unilateral pursuit of profit maximization which implies their non-subjection to a social plan executed with an over-riding social discipline. There is thus a divorce between private drive and social requirements. For this basic reason, incompatibilities between one part of the system and related parts tend to build up to the stage where the system cannot system and related parts tend to build up to the stage where the system cannot sustain them and they constitute a crisis. According to him, the system even generates crying absurdities as a normal mode of reproduction (Toyo 2002:25-26).

It is in this light that the recent global economic African leaders will do well to take steps to shield their people from the vagaries of future occurrence since, being inevitable, it is bound to recur sooner or later.

Focusing on the impact of the global economic crisis on the Nigerian economic and its implication for the social service sector, Ajakaiye and Fakiyesi (2009:14) stated that the consequences of the global financial crisis on growth and development in Nigeria are enormous and widespread. The first point of impact, according to them, is through the drop in the price of oil. This first point of impact, according to them, is through the drop in the price of oil. This is followed by the fall in the share price of the stock market. The combined effect of these two led to the depreciation of the naria exchange rate. Further worsening the situation is the withdrawal of foreign portfolio investment (hedge funds) from the Nigerian market. As of January 2009, foreign portfolio investors have withdrawn some US\$15 billion from the country's capital markets. Such massive withdrawals compound the crisis of confidence, which has further complicated the capital market recovery process. The transmission of these impacts to the real and financial sector ill surely hamper growth and development of the Nigerian economy. Lower growth would also mean a slowdown in the fight against poverty. Worsening poverty removes further the prospects of attaining the internationally agreed targets for halving the number of the poor within the framework of the MDGs by the year 2015. They stated that in the face of dwindling foreign exchange earnings, the CBN had to evolve management tactics that indirectly support the naira, and whose overall impact was less budgetary allocation at all tiers of government to growth and development enhancing programmes and high cost of importation for critical infrastructure development, as in the power and health sectors. 


\section{References}

Abdul, A (2009). 'The Effects of Global Financial crisis on Nigerian Economic.' www.rrojasdank.info/crisisdb/onnigeria09.pdf

Abdullahi, I. (2009), "The Effect of Global Economic Crisis on the New Democratic Nigeria. Being a paper presented at the National Conference on a Decade of Democracy (1999 - 2009): Reflections on Nigeria's Fourth Republic", held at IBB University, Lapai, Niger State, Nigeria, 18 - 20 May.

ACGS (2009). 'African Perspectives of the Global Economic and Financial Crisis, Including the Impact on Health.' Bing a Report prepared by the African Center for Gender and Social Development (ACGS).

Adekanye, T.O. et al. (2010) 'The Global Economic Crisis: Its Nature, Impact and the Conditions of Women in Africa.' American.edu...economic.../...FloroFasTornqvist2010-impact-of-global-economic-crisis.pdf.

Agaba, D. and Tenuche, (2010), "Managing the Global Economic Meltdown in a Consolidated Banking Sector of Nigeria: Rhetorics or Realities", Current Research Journal of Economic Theory, 2(1): 16-21.

Aham, U. (2008), "Oil and Development: More Money More Problems" TELL (Special Edition), No. 7, 26-28.

Ajakaiye, O. and fakiyesi, T. (2009). 'Global financial Crisis Discussion Series Paper 8: Nigeria> www.odi.org.uk/resources/download/3310.pdf.

Ajibade, A. (2009), "World Bank Budgets \$2bn. for Poor Countries", The Nation, August 5.

Akerele, O. (2009), "The State of Health of Nigerian Banks", BUSINESSDAY, June 27.

Alabi, W. (2009), "Banking Distress Alert", The Nation, February 6.

Aluko, M.E. (2008), "The Global Financial Meltdown: Impact on Nigeria's Capital Market and Foreign Reserves", 5.

Chete, L.N. (2009) 'Global financial Crisis and Challenges of Meeting the Economic-MDGs in Nigeria.' www. economicsunibuja. org/ nigeria economic.../ NES\%20 Global\%20financial\%20crisis\%and\%20Economic\%20MDGs\%.

Crotty, J. (2008) "Structural Causes of the Global Financial Crisis: A Critical Assessment of the 'New Financial Architecture' Political economy Research Institute (PERI) University of Massachusetts Amherst Working paper no. 180 September.

Eichengreen, B. (2004), "Financial Instability", in Bjorn, L. (ed). Global Crisis, Global Solutions. Cambridge: Cambridge University Press.

Eichengreen, B. and P. Richard (1987). The Anatomy of Financial Crisis. In Portes R. and A. Swoboda (eds.) Threats to International Financial Stability. Cambridge: Cambridge University Press.

Eme, O.I. and Asogwa, M. (2009). The Global Economic Crisis and the Challenges for Public Administration in Nigeria, Mimeo.

Enebeli-Uzor, S. (2008), "Global Financial Crisis: Emerging Challenges for Capital Markets",. Zenith Economic Quarterly, 3 (2) 70-75.

Fisher, H. (2010). 'Development Aid Rose in 2009 and most Donors will meet 2010 Aid Targets.' Development Co-operation Directorate (DCD-DAC), http://www/oecd.org/document/0,3746,en_2643_34447_44981579_1_1_1_1,00.html

Health-e (2010). 'AIDS Funds Fall Flat.' www.allafrica.com.

Hecker, H. (2010) 'The Effects of the Global economic Crisis: Examining the Impact on HIV \& AIDS funding Thus Far' http://www.consultancyafrica.com/index.php?option=com conten\&view=article\&ltemid=197.

Jacob, J. (2009) "The Global Financial Crisis and Leadership Challenges in Africa", African Journal of Contemporary Issues, Vol. 9 no, 3 , September pp 194-2002.

Kirigia et al.: (2011) 'Effects of the Global Financial Crisis on Funding for Health Development in Nineteen Countries of the WHO African Region.' BMC International Health and Human Rights 2011 11:4. http://www.biomedcentral.com/1472$698 \times / 11 / 4$

Kohler, G. and Tausch, A. (2002) Global Keynesianism: Unequal Exchange and Global Exploitation, Huntington NY: Nova Science.

Mangvwat, A.P. and Mangvwat, B.M. (2010) 'Food, Health and the Economic Depression in Contemporary Nigeria (1979-2009), in The Social: Sciences (5) 391-400, 2010.

Mitik, L. (2009) 'The Implications of the Global Economic Slowdown for Africa: A Synthesis' Center for Development consulting Addis Abada www.cdcet.com

Muanya, C. (2009) 'Doctors decry Reduction of Vote for Health in 2009 Budget' http://www.nigerianbestforum.com/index.php?

Musau, S (2010) 'Impact of Global Economic crisis on Health in Africa' in Africa's Health in 2010/AED, USAID, Washington D.C.. pdf.usaid.gov/pdf_docs/PNADQ002.pdf

Nwokah, M.G., Anyanwu, A. and Momodu, A.A. (2009), "Global Financial Meltdown and Implication for Marketing in Nigeria" Journal of Money, Investment and Banking Issues. 11, 61-77.

Okpanku, J. (2009), "Meltdown: How Operators, Governments Mitigate Impact", THISDAY June 12.

Oladesu, E. (2009), "How Lagos is Coping with Global Economic Meltdown", The Nation, June 30.

Sampson, E. (2008), "Global Financial Crisis: Recession, Depression and other Threats", Zenith Economic Quarterly, 3(4) 68-73.

Toyo, E. (2002) economics of Structural Adjustment: A Study of the Prelude to Globalization. Lagos: First Academic Publishers.

Trachtman, J.P (2009), "Global Financial Trouble: Causes, Cures, Responses", America Government on Facebook, May 1.

World Bank (2006). Getting Agriculture Going in Nigeria. Washington: The World. www.cnn.comhttp:llen.wikipediaorg/wiki/Listofbankruptoracquiredbanks.

WHO (2009a) 'The Financial Crisis and Global Health' Being Report of a High-Level Consultation World Health Organization, Geneva 19 January. P.3. Accessed on May 15, 2011.

WHO (2009b) 'Global Health Observatory' http://ww.who.int/countries/uga/nga/en/Health Profile. accessed 25/05/11 
